\title{
SCIENTIFIC REPORTS

\section{OPEN ST2 and regulatory T cells in the colorectal adenoma/carcinoma microenvironment: implications for diseases progression and prognosis}

\begin{abstract}
Guanglin Cui $\mathbb{1}^{1,2^{*}}$, Aping Yuan ${ }^{1}$, Zhenfeng $\mathrm{Li}^{1}$, Rasmus Goll ${ }^{3}$ \& Jon Florholmen ${ }^{3}$
ST2 (also known as IL1RL1) is the critical functional receptor for interleukin (IL)-33 in stimulating regulatory $T$ cell (Treg) expansion and function in physiological and pathological conditions. We examined the correlation between ST2 cell expression and FoxP3 positive Tregs in both colorectal adenoma and cancer (CRC) microenvironment by real-time PCR, immunohistochemistry (IHC) and double immunofluorescences. The clinicopathological and prognostic significance of cellular ST2positive cells and FoxP3-positive Tregs in patients with adenoma and CRC were evaluated. Real-time PCR results revealed increased expression levels of ST2 and FoxP3 mRNAs in both adenoma and CRC tissues as compared with control tissues. IHC analysis confirmed increased densities of ST2-positive cells in both the adenoma/CRC epithelium and stroma, which show a close positive linear association with the densities of FoxP3-positive Tregs in respective compartments. Pathological feature analysis showed that densities of ST2-positive cells in the tumor stroma were notably associated with degree of dysplastic grading in patients with adenoma, and disease stages and lymph node metastasis in patients with CRC. Kaplan-Meier survival curves suggested that CRC patients with high densities of ST2-positive cells in the stroma tend to have a shorter overall survival. We therefore concluded that increased densities of ST2-postive cells relate to Treg accumulation within the adenoma/CRC microenvironment, suggesting the IL-33/ST2 pathway as a potential contributor for immunosuppressive milieu formation that impact disease stage and prognosis in patients with CRC.
\end{abstract}

Colorectal cancer (CRC) is one of the most common malignant diseases worldwide. The progression of CRC is not only determined by CRC cells themselves but also by their immune microenvironment ${ }^{1}$. Although high densities of immune cells have been observed in the CRC microenvironment, most CRCs still progress invasively with the development of metastasis. Most likely, these patients do not develop a satisfactory antitumor immune capacity and some CRC cells have escaped the immune surveillance control ${ }^{2}$. Indeed, current scientific data strongly suggest that an immunosuppressive network is established in the CRC microenvironment wherein immune suppressive cells and cytokines play a critical role in inhibiting the host effective antitumor function, thereby promoting CRC progression and metastasis ${ }^{3-5}$. Therefore, there is a great interest in studying the contributing factors of immunosuppressive microenvironment formation during CRC development ${ }^{6,7}$.

Interleukin (IL)-33, which is a member of the IL-1 cytokine family, regulates a Th2 response but also a Th1 response through natural killer cells, CD8 T cells and $\gamma \delta \mathrm{T}$ cells ${ }^{8-11}$ and contributes to the generation of immunosuppressive cells ${ }^{12-15}$. Current evidence regarding the role of IL-33 in the CRC development suggest that IL-33 is involved in the pathogenesis of $\mathrm{CRC}^{1,16-18}$, and IL-33 significantly promotes the establishment and progression of CRC in both mice and humans ${ }^{1,18-22}$. Mechanisms whereby IL-33 promotes the development of CRC remain unclear, though several potential mechanisms have been hypothesized and evaluated ${ }^{18,23-25}$. Mertz KD et al. revealed that the promoting effect of IL-33 on the development of CRC in mice does not directly affect the proliferation of tumor cells in animal CRC models ${ }^{20}$. Other studies have demonstrated that IL-33 can greatly influence various immune cells including regulatory $\mathrm{T}$ cell (Treg) during differentiation, immune responses and

${ }^{1}$ Department of Gastroenterology, the Second Affiliated Hospital of Zhengzhou University, Henan, China. ${ }^{2}$ Faculty of Health Science, Nord University at Campus Levanger, Levanger, Norway. ${ }^{3}$ Department of Gastroenterology \& Nutrition, University Hospital of North Norway, Tromsø, University of Tromsø, Tromsø, Norway. *email: guanglin. cui@nord.no 
homeostasis ${ }^{10,26}$. Thus, one of the proposed mechanisms is through the regulation of Treg expansion and function within the tumor microenvironment and by creating an pro-tumor microenvironment and diminishing innate anti-tumor immunity ${ }^{15,17,26-29}$. CD4+ and CD25+ Tregs, which are characterized by the expression of the master regulatory transcription factor forkhead box P3 (FoxP3), represent a subset of CD4+ T cells with a strong immunosuppressive capacity. In recent mice and human studies, an important role for Tregs in the development and progression of CRC has been demonstrated ${ }^{30-36}$. Extensive data have shown that the density of Tregs is significantly increased in the CRC microenvironment ${ }^{30,31,34,35,37-39}$, and elevated proportions of Tregs may have prognostic significance in patients with $\mathrm{CRC}^{33,40-43}$. More recently, a study performed in APC Min/+ mice examined the expression of Tregs in premalignant adenomatous lesions ${ }^{44}$. The results revealed that a high density of Tregs in the stroma was closely associated with the development of adenomatous polyps in the intestine ${ }^{44}$. We recently reported that the increase of FoxP3-positive Tregs is accompanied by the increased expression of the immunosuppressive cytokine IL-10 along the human colorectal adenoma-carcinoma sequence ${ }^{44}$. These findings suggest an association between Treg activation and the development and progression of CRC. Thus, there is currently a great interest in studying the regulatory mechanisms of Treg generation and function within the tumor microenvironment. Abundant evidence indicates that IL-33 is critically important for the generation and maintenance of Tregs in various colonic diseases ${ }^{12,15,45-47}$. Since ST2 (also known as IL-1RL1) is the critical functional receptor for IL-33 in regulating immune cell expansion and immune response, the importance of IL33/ST2 axis in the generation of immunosuppressive microenvironment in human tumors has got an intensively attention ${ }^{18,48-50}$. Current evidence have shown that a remarkable change in ST2 expression has been observed during the colorectal neoplastic transformation, which leads to the formation of adenoma ${ }^{16}$ and $\mathrm{CRC}^{20}$. In addition, we have previously demonstrated that several types of cells, including tumor cells, stromal cells and immune cells, express ST2 in human adenomas/CRCs ${ }^{1}$. Moreover, Mertz KD et al. reported that deficiency of ST2 could significantly protect the development of chemic carcinogen-triggered CRC in mice ${ }^{20}$. Another animal study showed that blocking ST2 signal by a specific antibody administration in the ApcMin/+ adenomatous polyps mice could remarkably inhibit the occurrence of polyps number and size compared to control mice ${ }^{16}$. Therefore, precisely study the significance of ST2 expression in the context of Treg biology might greatly help to understand IL-33's role involved in the pathogenesis of CRC. Indeed, Pastille et al. ${ }^{51}$ have studied the important role of Tregs in the development of CRC in ST2fl/fl;Foxp3-Cre mice, with Treg-specific ST2 deletion, they have found that IL-33/ST2 axis plays a central role in shaping an immunosuppressive environment during intestinal tumorigenesis. Landskron $\mathrm{G}$ et al. ${ }^{52}$ investigated the potential role of IL-33/ST2 pathway in promoting metastasis of cancer cells by using CRC cell lines and CRC tissues. They reported that IL-33/ST2 axis in tumor microenvironment contributes to invasion and metastasis in left-sided CRC, most likely by the interaction between can associated fibroblasts and epithelial tumor cells and activating desmoplasia. Moreover, Li and colleagues ${ }^{53}$ analyzed IL-33 gene expression in human CRC tissues and carried out gene enrichment analysis with TCGA Data Portal, and studied CRC proliferation in vivo by inoculating MC38 tumors in IL-33 transgenic mice and investigated the cell proliferation in vitro with primary CRC cells isolated from fresh human CRC tissues, human CRC cell line HT-29 and mouse CRC cell line MC38. They concluded that IL-33 facilitates proliferation of colorectal cancer dependent on COX2/PGE2. Interestingly, Tregs are also reported to be a cellular source for COX-2 $2^{54,55}$ and IL-33 could potentially stimulate Treg expansion and function via its functional receptor ST2 $2^{12,15,56}$. These studies provided novel evidence to support the notion that Tregs contribute to the development of CRC. However, these results obtained from animal and cell line studies are waiting to be validated in human CRCs, particularly across the colorectal adenoma (premalignant lesion)-cancer sequence (malignant lesions).

Therefore, we designed this study to define dynamic relationship between ST2 and Tregs in different histological compartments across the colorectal adenoma-cancer sequence, evaluate its clinicopathological/prognostic significance in patients with adenomas and CRCs.

\section{Results}

The mRNA expression levels of ST2 and FoxP3 in adenoma and CRC tissues. The quantitative PCR results are presented in Fig. 1. Compared with the controls, the mRNA expression of ST2 (Fig. 1A) were increased to a $\sim 3$-fold higher level in the adenoma tissues and $\sim 2.3$-fold higher level in the CRC tissues respectively (both $P<0.05$ ). The expression level of ST2 mRNA was slightly higher in the adenoma tissues than that in the CRC tissues $(P>0.05)$.

Similarly, the mRNA expression of FoxP3 (Fig. 1B) were increased to a $\sim 4.8$-fold higher level in the adenoma tissues and to a 5.6-fold higher level in the CRC tissues (both $P<0.05$ ).

Cellular expression of ST2 and FoxP3 in the adenoma/CRC microenvironment. H\&E stained images were supplied in Supplementary Data Fig. 1. IHC were used to examine cellular expression of ST2 and FoxP3 in the adenoma/CRC microenvironment.

Following IHC staining, ST2-positive cells were observed in both the epithelium and lamina propria in normal controls (Fig. 2A), adenomas (Fig. 2B) and CRCs (Fig. 2C). Increased abundance of FoxP3-positive Tregs was also demonstrated in both the adenoma/CRC epithelium and stroma (Fig. 2E,F), compared with the controls (Fig. 2D).

The results of the semi-quantitative grading confirmed the above mentioned IHC results and revealed a trend of increasing densities of ST2-positive cells in the adenoma/CRC epithelium (Fig. 3A) and stroma (Fig. 3B). Notably, the density of ST2-positive cells in adenoma epithelium was higher than that in the control and CRC (see Fig. 3A, adenoma vs. control and adenoma vs. CRC, both $P<0.05$ ). Increased densities of FoxP3-positive Tregs were also observed in both the adenoma/CRC epithelium (Fig. 3C) and stroma (Fig. 3D) compared with the controls. The density of FoxP3-positive Tregs was even higher in the CRC stroma than that in the adenoma stroma (Fig. 3D, $P<0.01$ ). 
A

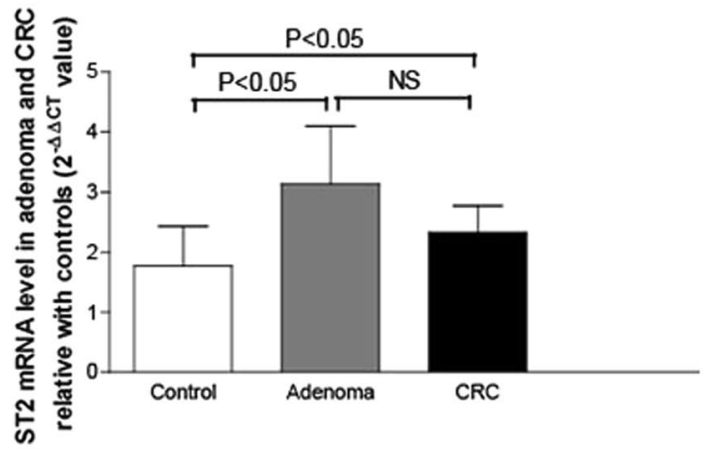

B

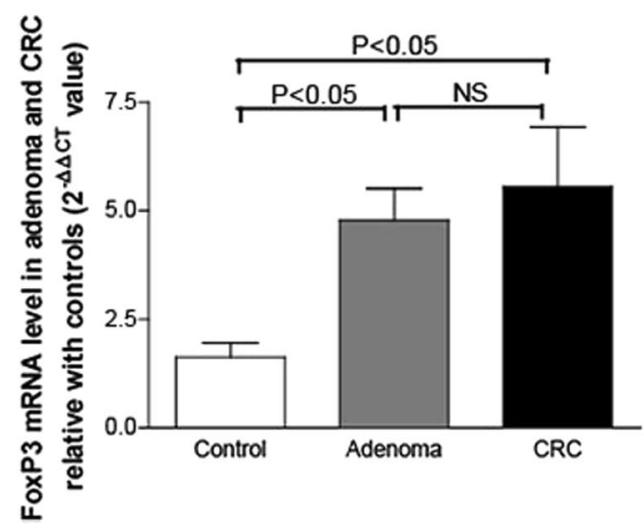

Figure 1. mRNA expression level of ST2 and FoxP3 in the adenomas and CRC tissues. The mRNA expression level of ST2 determined by real-time PCR was significantly increased in the adenoma tissues (grey bar in A) compared to the normal controls (white bar in $\mathbf{A}, P<0.05$ ). It was also significantly higher in the CRC tissues (black bar in $\mathbf{A}$ ) than in the normal controls (white bar in $\mathbf{A}, P<0.05$ ) but slightly lower than that in the adenoma tissues (grey bar in $\mathbf{A}$ ). As seen in $\mathbf{B}$, the expression level of FoxP3 mRNA showed an increasing trend along the adenoma-carcinoma sequence. Increased expression of FoxP3 mRNA was started from the adenoma stage (grey bar in B) and even higher in the CRC stage (black bar in B) compared to the normal controls (white bar in $\mathbf{B}$, both $P<0.05)$. NS: no significant, $P>0.05$.

Phenotypic analysis of ST2-positive cells in the adenoma/CRC stroma showed that many ST2-positive cells were $\mathrm{CD} 3$ positive lymphocytes (Fig. 3E).

To check whether FoxP3-positive cells infiltrated into adenoma/CRC epithelium were Tregs instead of epithelial cells, double immunohistochemistry with FoxP3/CD3 antibodies was performed. The image showed that FoxP3-positive cells in the adenoma/CRC epithelium were positive for CD3 (See Supplementary Data Fig. 2) and confirmed that the cells were lymphocytes, but not adenoma/CRC epithelial cells.

Spearman's R coefficient analysis of correlation between ST2 and FoxP3 at mRNA and cellular levels in the adenoma/CRC microenvironment. The analysis showed that the expression level of ST2 mRNA in both adenoma and CRC tissues were not correlated with the expression level of FoxP3 mRNA (see Table 1). However, ST2 expression at cellular level in the adenoma stroma was correlated with the density score of FoxP3-positive Tregs in the same compartment. The density of ST2-positive cells in both the CRC epithelium and stroma were correlated with the density scores of FoxP3-positive Tregs (Table 1).

Analysis of ST2-positive cell and FoxP3-positive Treg densities in the tumor microenvironment against clinicopathological variables in patients with adenoma or CRC. We previously found that cytokines and their receptors may be expressed by a variety of cellular phenotypes in the CRC microenvironment ${ }^{1,4,5,57,58}$. Therefore, we analyzed correlations between the densities of ST2-positive cells and FoxP3-positive Tregs in different compartments of the adenoma/CRC microenvironment and the clinicopathological variables in patients with adenoma/CRC.

The results revealed that the density of ST2-positive cells in the adenoma stroma correlated with dysplastic degree grading, adenoma patients with high grading of dysplasia (HGD) tended to have a higher density of ST2-positive stromal cells than those with low grading of dysplasia (LGD) (Fig. 4A). Adenomas with villous feature has been shown to have a high risk to develop $\mathrm{CRCs}^{59}$. However, we could not find such correlation between adenomas with tubular type and those with villous features (Tubular vs. Tubularvillous +Villous: $\mathrm{P}>0.05$, see Fig. 4A). In addition, densities of ST2-positive adenoma epithelial cells correlated neither with histological types nor dysplastic degree grading (Supplementary Data Fig. 3A). In the CRC, the density of ST2-positive stroma cells was significantly associated with advanced TNM stage and node involvement (Fig. 4B). However, densities of ST2-positive cells in the CRC epithelium were not correlated with clinicopathological variables (Supplementary Data Fig. 3B).

The density of FoxP3-positive Tregs in both adenoma epithelium and stroma correlated neither with histological types nor dysplastic degree grading (Supplementary Data Fig. 3C,D). CRC patients with node involvement exhibited a higher density of FoxP3-positive Tregs in the tumor stroma compared to those without node involvement (Fig. 4C). However, densities of FoxP3-positive Tregs in the CRC epithelium were not correlated with clinicopathological variables (Supplementary Data Fig. 3E).

Kaplan-Meier survival curves analyze the prognostic significance of ST2-positive cell and FoxP3-positive Treg densities in patients with CRC. Kaplan-Meier analysis revealed that CRC patients with high densities of ST2-positive cells and FoxP3-positive Tregs in the tumor stroma tended to have a significantly shorter overall survival time compared with patients with low densities of ST2-positive cells and FoxP3-positive Tregs (Fig. 5A,B). 

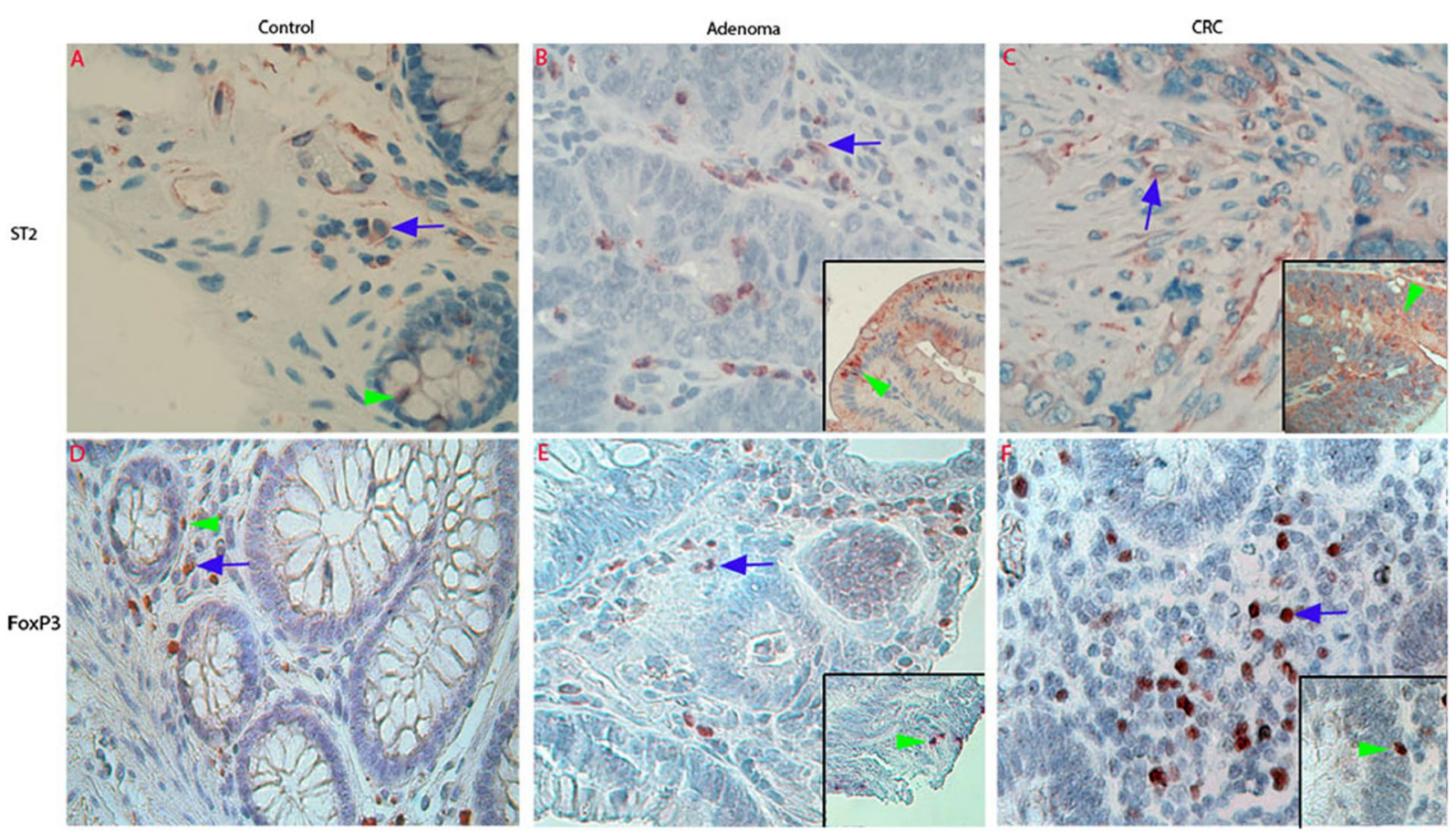

Figure 2. Photographic representations and density analysis of ST2-positive cells and Foxp3-positive Tregs in normal colorectal, adenoma and CRC tissues examined with immunohistochemistry (IHC). IHC images in first panel of Fig. 2 showed that ST2-immunoreactivity (IR) in the control tissues was observed in both the epithelium (green arrowhead in $\mathbf{A}$ ) and lamina propria (blue arrow in $\mathbf{A})$. In the adenoma and CRC tissues, increased ST2-IR was observed in both the adenoma (green arrowhead in inserted image in B)/CRC epithelium (arrowhead in inserted image in C) and adenoma (blue arrow in B)/CRC stroma (blue arrow in C). As seen in second panel of Fig. 2, low density of Foxp3-positive Tregs were observed in control lamina propria (blue arrow in D). However, dense Foxp3-positive Tregs were found in both the adenoma (blue arrow in E)/CRC stroma, (blue arrow in F), and some were infiltrated into adenoma/CRC epithelium (green arrowhead in inserted images in E,F). (A-F: IHC, counterstained with hematoxylin, original magnification $200 \times$ ).

The densities of neither ST2-positive cells (Supplementary Data Fig. 4A) nor FoxP3-positive Tregs (Supplementary Data Fig. 4B) in the CRC epithelium were correlated with the survival rate of patients with CRC.

Double immunohistochemistry images revealed an co-expression of ST2 with FoxP3. Double immunohistochemistry images revealed that many of Tlymphocytes in the adenoma stroma (arrow pointed in Fig. 6A) and CRC stroma (arrow pointed in Fig. 6B) were positive for both FoxP3-IR (brown color) and ST2-IR (red color) in the representative sections. In addition, ST2-IR was also observed in the epithelial cells (arrowhead pointed in Fig. 6B).

\section{Discussion}

The protumor effect of IL-33/ST2 pathway has been demonstrated in various types of cancers ${ }^{1,19,20,60-63}$. In this study, we examined expression of ST2 and its association with Treg accumulation in the adenoma/CRC microenvironment as well as the clinicopathological significance in patients with adenoma/CRC. Results showed that the expression of both ST2 and FoxP3 at the mRNA and cellular levels were significantly increased in the adenoma/ CRC microenvironment. Moreover, the density of ST2-positive cells in the tumor stroma was correlated with the dysplastic degree in the adenoma, which is one of the important histological hallmarks for the progression of an adenoma towards to a CRC. Densities of ST2-positive cells in the CRC stroma were correlate with advanced TNM stage, node involvement and overall survival rate after surgery in patients with CRC. In addition, ST2 was frequently expressed in FoxP3-positive Tregs in the CRC microenvironment. These findings suggest that ST2 is involved in the regulatory effect of IL-33 on progression and prognosis of CRC.

Accumulating studies have demonstrated the importance of IL-33/ST2 pathway in regulating immune cell generation and function ${ }^{12,15}$. IL-33 can significantly enhance the recruitment of immunosuppressive immune cells into the tumor site, where these cells have a strong impact on immune microenvironment remodeling ${ }^{15,17,29,51}$. Exogenously administered recombinant mouse IL-33 significantly induces ST2-positive Tregs accumulated in tumor masses. In contrast, neutralizing IL-33 or ST2 by administration of antibodies remarkably decreases the density of ST2-positive Tregs inside tumor masses in CRC-bearing mice ${ }^{63}$. A more recent investigation has showed that the IL-33/Treg axis significantly contribute to the creating of tumor-promoting immune environment as seen in chronic inflammation condition ${ }^{29}$. Pastille $\mathrm{E}$ et al. further revealed that Tregs in the CRC microenvironment could preferentially upregulate ST2 expression in mice. Their transcriptomic and flow cytometry analyses demonstrate that ST2 expression induces a more activated and migratory phenotype in FoxP3 positive Tregs, and results in an intensively accumulation in the tumor microenvironment. Genetic ablation of ST2 could remarkably reduce 
A
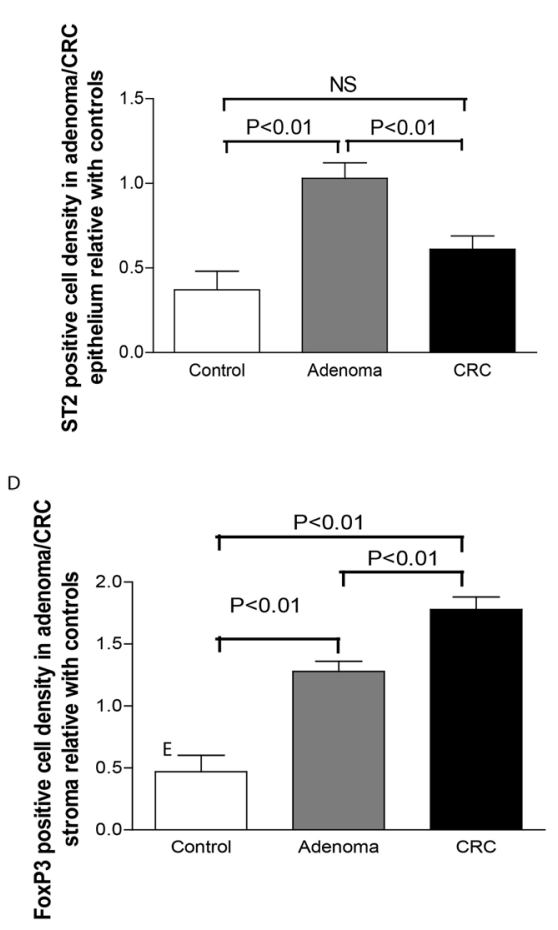
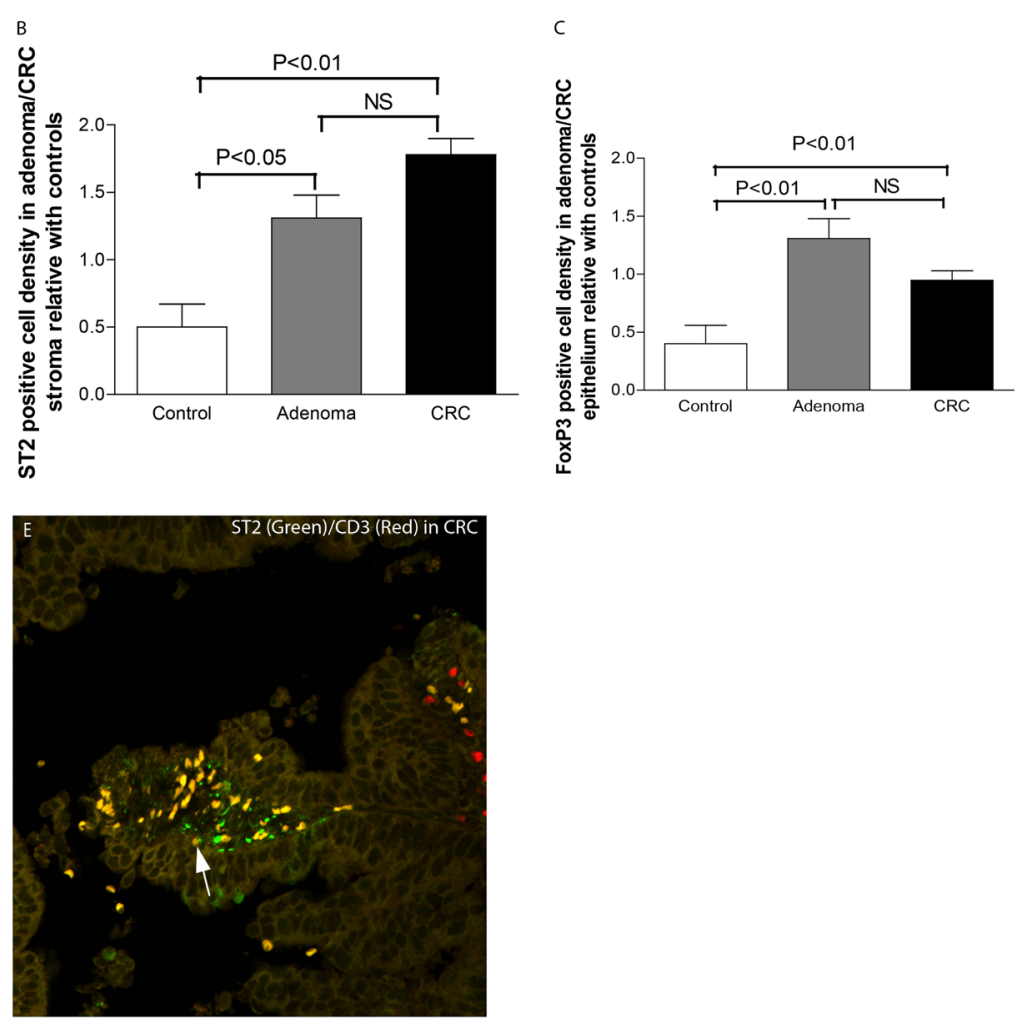

Figure 3. Density and phenotypical analysis of ST2-positive cells and FoxP3-positive Tregs in the adenoma/ CRC stroma. Semiquantitative data showed that the scores of ST2-positive cells (A,B, epithelium and stroma respectively) and FoxP3-positive Tregs (C,D, epithelium and stroma respectively) in both the adenoma and CRC were increased. The density of ST2-positive cells and FoxP3-positive Trges were even higher in the adenoma epithelium (A,C, grey bar) and that in the CRC epithelium (A,C, black bar). Further phenotypic analysis of ST2-positive cells (green color in E,F) in the adenoma/CRC stroma defined that most positive cells were colocalized with CD3-positive labelled (red color in E) T lymphocytes (white arrow point in E) and some were SMA-alpha-labelled (red color in $\mathbf{F}$ ) myofibroblasts (white arrow point in $\mathbf{F}$ ). (E,F, confocal images, original magnification $200 \times$; counterstaining was not applied).

Treg density, but enhance the density of effector CD8 positive T cells in the tumor microenvironment, thereby inhibiting CRC development in mice ${ }^{51}$. These data suggested that the IL-33/ST2 pathway plays an essential role in the regulation of Treg activation and function. In human CRCs, we and other group have shown that expression levels of IL-33 and ST2 are significantly increased ${ }^{1,19}$. Our present results demonstrated that increased expression of ST2 mRNA was increased in both adenoma and CRC tissues. Interestingly, the expression level of ST2 mRNA in the adenoma tissues was higher than that in the CRC tissues, which might imply that increased ST2 is an early event occurred in the adenoma stage of colorectal adenoma-carcinoma sequence and involved in the formation of adenoma. Our quantitative PCR data also showed that bot the expression of ST2 and FoxP3 mRNAs were increased in adenomas and CRCs respectively compared to the controls. Because ST2 is the primary functional receptor for IL-33, which contributes to Treg expansion and function ${ }^{12,14,56}$, our present results may imply that ST2 overexpression correlates to Treg accumulation in both the adenoma and CRC. IHC results confirmed that both densities of ST2-positive cells and FoxP3-positive Tregs were increased in the different compartments of adenoma/CRC microenvironment, and further double immunofluorescence images revealed that ST2 was frequently expressed in FoxP3-positive cells in the adenoma stroma. In addition, correlational analysis showed that cellular expression of ST2-positive stromal cells in the adenoma was correlated with the expression of FoxP3-positive Tregs in the adenoma stroma. Similar correlations between ST2-positive cells and FoxP3-positive Tregs in both the CRC epithelium and stroma were also found. These analysis may imply an regulation role of Tregs by IL-33 in during the establishment of CRC. Thus, one of likely explanations is that ST2 is a potential functional mediator for IL-33 in stimulating Treg accumulation in the adenoma/CRC microenvironment. Although FoxP3 is a commonly used biomarker for Tregs, however, we can still see that not all ST2 positive cells appear to be positive for FoxP3 in the Fig. 6. Indeed, a previous publication showed that FoxP3 is not exclusively expressed on bona fide CD4/CD25 positive Tregs and it is also expressed in CD44 positive effector and CD44/CD62L positive memory T cells upon stimulation $^{64}$. Thus, we could postulate that ST2 might be also mediate the IL-33's effect in other types of immune cells.

Moreover, previous studies have reported that IL-33/ST2 in human cancers is expressed in a variety of cells, including epithelial cells, stromal cells, infiltrating lymphocytes and Tregs, and microvessels $s^{1,16,20,60,65}$. In the CRC sections, our IHC results clearly demonstrated the increased expression of ST2-IR in the adenoma/CRC epithelium and tumor stroma, supporting the possibility that ST2 in the adenoma/CRC microenvironment is derived from a mixture of cell types. 


\begin{tabular}{|c|c|c|c|c|c|c|}
\hline & \multicolumn{3}{|c|}{ ST2 in adenoma } & \multicolumn{3}{|c|}{ ST2 in CRC } \\
\hline & $\begin{array}{l}\text { Tissue } \\
\text { mRNA }\end{array}$ & $\begin{array}{l}\text { Cells in } \\
\text { epithelium }\end{array}$ & $\begin{array}{l}\text { Cells in } \\
\text { stroma }\end{array}$ & $\begin{array}{l}\text { Tissue } \\
\text { mRNA }\end{array}$ & $\begin{array}{l}\text { Cells in } \\
\text { epithelium }\end{array}$ & $\begin{array}{l}\text { Cells in } \\
\text { stroma }\end{array}$ \\
\hline \multicolumn{7}{|c|}{ FoxP3 in adenoma } \\
\hline \multicolumn{7}{|c|}{ Tissue mRNA } \\
\hline$r$ & 0.1226 & & & & & \\
\hline$P$ & 0.4967 & & & & & \\
\hline \multicolumn{7}{|c|}{ Cells in epithelium } \\
\hline$r$ & & 0.3565 & & & & \\
\hline$P$ & & 0.0577 & & & & \\
\hline \multicolumn{7}{|c|}{ Cells in stroma } \\
\hline$r$ & & & 0.3899 & & & \\
\hline$P$ & & & 0.0365 & & & \\
\hline \multicolumn{7}{|c|}{ FoxP3 in CRC } \\
\hline \multicolumn{7}{|c|}{ Tissue mRNA } \\
\hline$r$ & & & & 0.3149 & & \\
\hline$P$ & & & & 0.0962 & & \\
\hline \multicolumn{7}{|c|}{ Cells in epithelium } \\
\hline$r$ & & & & & 0.4279 & \\
\hline$P$ & & & & & 0.0053 & \\
\hline \multicolumn{7}{|c|}{ Cells in stroma } \\
\hline$r$ & & & & & & 0.4553 \\
\hline$P$ & & & & & & 0.0028 \\
\hline
\end{tabular}

Table 1. Spearman's $R$ coefficient analysis of correlation between ST2 and FoxP3 at mRNA and cellular levels in the adenoma/CRC microenvironment.

With respect to the relationship between the density scores of ST2-positive cells and FoxP3-positive Tregs in different compartments and the clinicopathological features of patients with adenoma/CRC, we found that increased density of ST2-positive stromal cells was correlated with dysplastic degree grading in the adenoma, and with advanced TNM stages and lymph node involvement in the CRC. In addition, the increased density of FoxP3-positive Tregs in the CRC stroma was correlated with lymph node involvement. Taken together with previous findings of Tregs in suppressing host anti-tumor immunity ${ }^{51,54}$, our current finding may reflect the hypothesis that Tregs promote lymph node metastasis by limiting antitumor immunity and supporting tumor immune evasion. Current findings somewhat differ from our previous reports in which the mRNA expression levels of ST2 and FoxP3 mRNAs were not associated with clinicopathological features in patients with $\mathrm{CRC}^{1,66}$. This discrepancy may be explained by the fact that there are significant differences between the two techniques. Advantages and disadvantages of these two techniques have been discussed for years: ${ }^{67-69}$ we previously used quantitative real-time PCR as a high sensitive technique to quantify ST2 or FoxP3 at the mRNA level on only a tiny fraction of adenoma/CRC specimens. In current study, we used immunohistochemistry to precisely examine the cellular expression of ST2 and FoxP3 in different compartments of adenoma/CRC microenvironment on whole paraffin sections, as immunohistochemistry is an ideal technique to observe the location and semiquantitative expression of certain proteins in cellular and tissue levels. Therefore, combining these two techniques may be a better way to investigate the relationship between ST2 and Tregs within the tumor microenvironment in future studies.

Previous studies have also reported that IL-33 expression is correlated with survival in patients with various cancers $^{61,70,71}$. We therefore performed a Kaplan-Meier analysis to investigate the relationship between the density scores of ST2-positive cells and FoxP3-positive Tregs located in different compartments (CRC epithelium/ stroma) of the CRC microenvironment and the survival rate of patients with CRC. Our results revealed that densities of ST2-positive cell and FoxP3-positive Tregs in the CRC stroma, but not that in CRC epithelium, predicate the overall survival time after surgery. Since we have a small cohort of CRC patients with survival data in this study, it is necessary to extrapolate the conclusion in large scale samples in future studies.

Taken together with the results of previous studies, our current findings suggest that increased expression of ST2 in the tumor microenvironment, as a primary functional receptor for IL-33, was started from the adenoma stage and persisted to the CRC stage, which suggest that ST2 could be the functional receptor for IL-33 in promoting the development of adenoma/CRC (Fig. 7). The density of ST2-positive cells in the adenoma/CRC stroma parallels the increased density of FoxP3-positive Tregs in the adenoma/CRC microenvironment, and is associated with the some advanced clinicopathological variables in both the adenoma/CRC and prognosis in patients with CRC. Therefore, a future priority is to validate the current findings in a large cohort of patients with adenoma/CRC.

\section{Materials and methods}

Patients and biopsies. Fifty resected CRC specimens (male/female: 42/8; average age 42-89 years), 50 resected adenoma specimens (male/female: 31/19, ages 43-92 years) and 30 control colorectal tissues from health subjects with no pathological evidence by colonoscopic and microscopic examinations (male/female: 20/10; age 24-79 years) were included in this study. None of the included patients or control subjects had a history of regular 

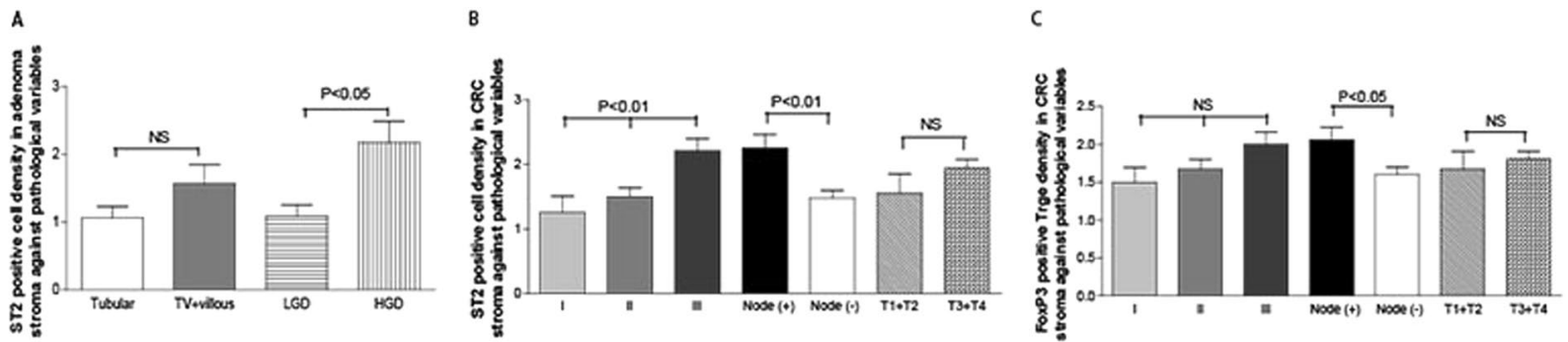

Figure 4. Clinicopathological analysis of ST2-positive cells and FoxP3-positive Tregs in patients with adenomas and CRCs. Further clinicopathological analysis revealed that increased densities of ST2-positive cells in the adenoma stroma (A) correlated with the degree of dysplasia, patients with high grade of dysplasia (HGD) tend to have a higher density of ST2-positive stromal cells than those with low grade of dysplasia (LGD). The density of ST2-positive cells in the CRC stroma correlates with TNM stages and node involvement (B), and the density of FoxP3-positive Tregs in the CRC stroma correlated with node involvement (C). NS: no significant, $P>0.05$.

A

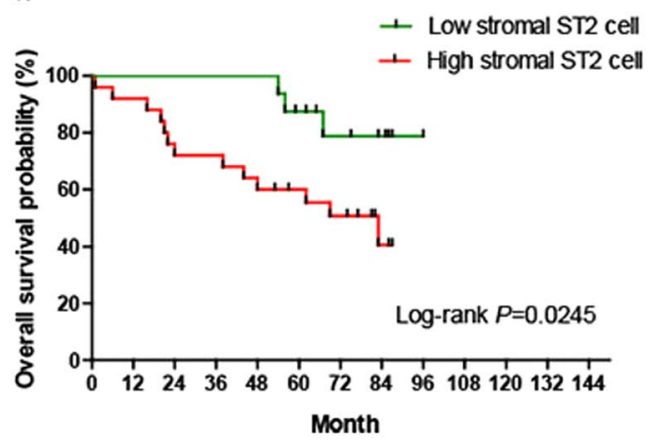

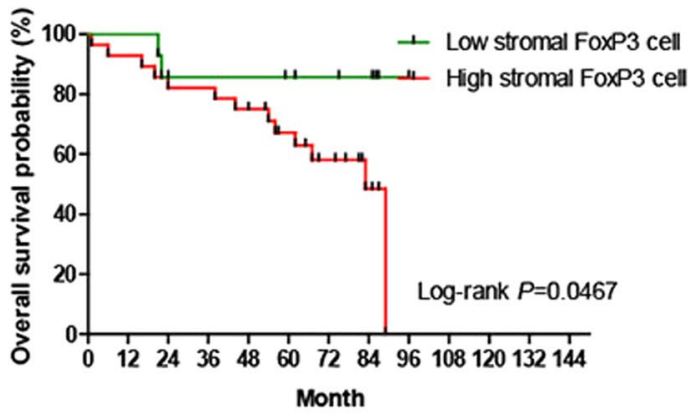

Figure 5. The Kaplan-Meier analysis of overall survival differences in CRC patients with differing density scores of ST2-positive cells and FoxP3-positive Tregs. The Kaplan-Meier analysis revealed that the density scores of ST2-positive cells (A) and FoxP3-positive Tregs (B) in the CRC stroma predicate the overall survival time in patients with CRC. CRC patients with high densities of ST2-positive cells and FoxP3-positive Tregs in the tumor stroma did have a significantly shorter overall survival time compared with those with low densities of ST2-positive cells and FoxP3-positive Tregs.
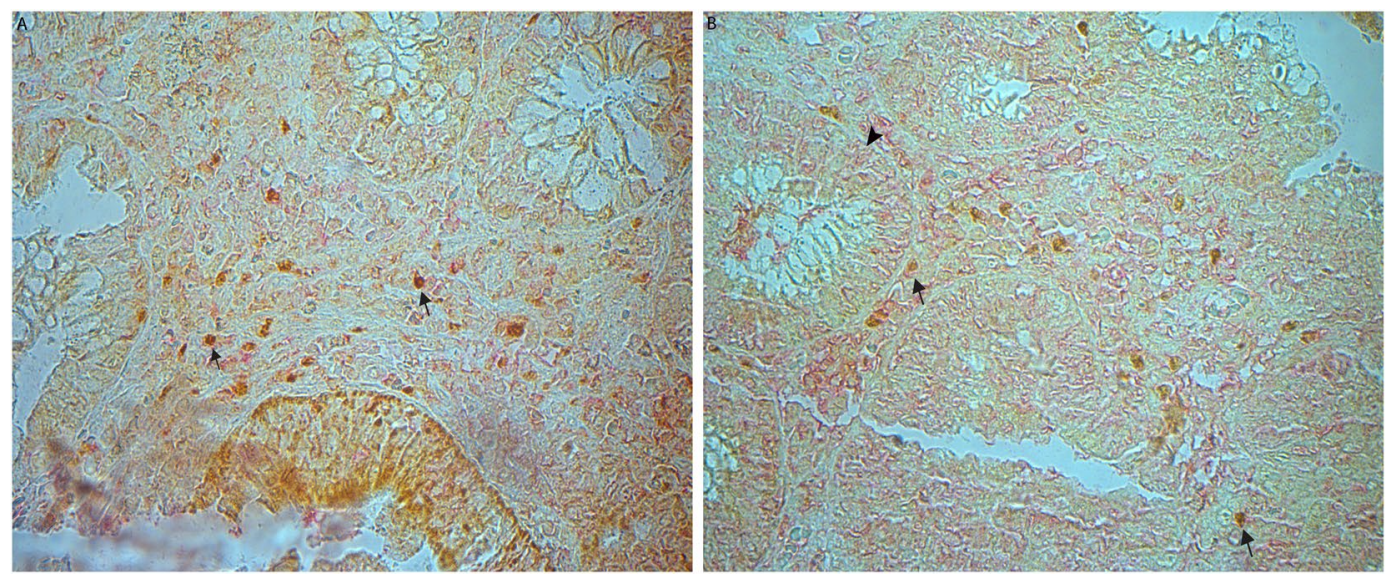

Figure 6. Photographic representations of ST2 expressed in FoxP3-positive Tregs in the adenoma stroma. Double immunohistochemistry images revealed that many FoxP3-labelled (red color in A) Tregs expressed ST2-IR (brown color in $\mathbf{B}$ ) in a represent adenoma section. (A,B, double immunohistochemistry images, original magnification $400 \times$; counterstaining was hematoxylin). 


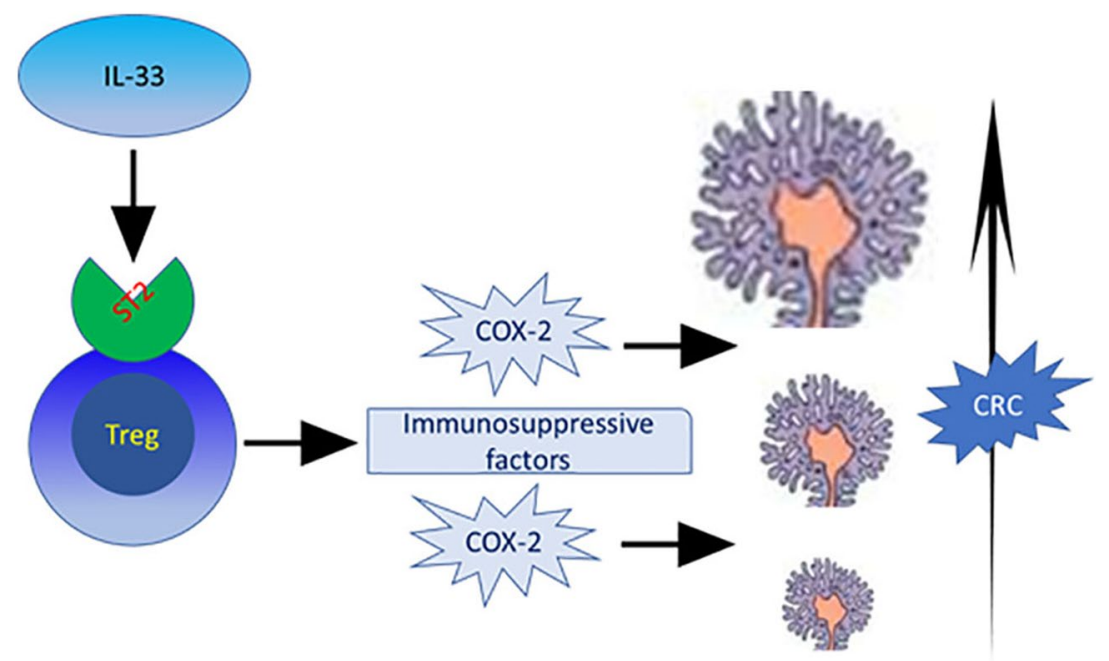

Figure 7. A schematic representation of the potential role of IL-33 functional receptor ST2 in contributing to the development of colorectal cancer.

\begin{tabular}{|l|l|l|l|l|l|l|l|l|l|l|l|l|}
\hline & \multirow{4}{*}{} & \multicolumn{4}{l}{ TNM } & \multicolumn{4}{l|}{ Invasion depth } & \multicolumn{2}{l|}{ Lymph node } \\
\cline { 2 - 11 } & N & I & II & III + IV & T1 & T2 & T3 & T4 & Positive & Negative \\
\hline CRC & 50 & 9 & 20 & 21 & 4 & 12 & 28 & 6 & 21 & 29 \\
\hline & & Histological types & \multicolumn{5}{|l|}{ Degree of dysplasia } & & \\
\hline & & tubular & tubulovillous & villous & LGD & HGD & & & \\
\hline Adenoma & 50 & 33 & 15 & 2 & 40 & 10 & & & \\
\hline
\end{tabular}

Table 2. Basic information of patients with adenoma and CRC. LGD: lower grade dysplasia; HGD: high grade dysplasia.

use of immunomodulation treatment or chemotherapy. All biopsies were collected from the University Hospital of North Norway between August 2003 and December 2008, and detailed information on these adenomas and CRCs is summarized in Table 2. All biopsies were divided into two pieces. One piece was routinely embedded in paraffin, and sections were subsequently cut and stained with hematoxylin and eosin $(H \& E)$, another piece was embedded in RNA later solution for total RNA extraction and mRNA quantification. Routine histological diagnosis of all biopsies was performed in the Department of Clinical Pathology at the University Hospital of North Norway. The study protocol was approved by the Regional Ethical Committee of Northern Norway, and written informed consent was obtained from all included patients.

Quantitative real-time PCR. The extraction of total RNA, reverse transcription of mRNA and real-time quantification of cDNA for the controls, adenomas and CRCs were performed using our previously published methods ${ }^{1,72}$. The primers for ST2 were purchased from Life Technologies (Cat\# No. 4331182; Grand Island, NY, USA; which allows to amplify the membrane-bound but not the soluble ST2 isoform, as indicated by the manufacturer), FoxP3 and the housekeeping gene $\beta$-actin are also listed in our previous publications ${ }^{1,66}$ (see Table 3). The mRNA expression levels of ST2 and FoxP3 in colorectal adenomas and CRCs were measured according to the cycle threshold (CT) value relative to that of normal tissue. In brief, the expression levels of examined ST2 or FoxP3 mRNAs in the adenoma and CRC tissues were measured by CT cross-point value in relative to that of control tissues as fold difference $(\mathrm{N})=2^{-\Delta \Delta \mathrm{CT}}, \Delta \mathrm{CT}=\mathrm{CT}_{\text {examined gene ( } \mathrm{ST2} \text { or FoxP3) }}-\mathrm{CT}_{\text {beta-actin, }} \Delta \Delta \mathrm{CT}=\Delta \mathrm{CT}_{\text {Adenoma }}$ or $\mathrm{CRC}^{- \text {average }} \Delta \mathrm{CT}_{\text {normal }}$ as described in our recent publication ${ }^{1,5,57}$.

Immunohistochemistry (IHC). To examine the expression pattern of ST2-positive cells and FoxP3-positive Tregs in the adenoma/CRC microenvironment, IHC staining was performed on 4 - $\mu \mathrm{m}$ paraffin-embedded sections from controls, adenomas and CRC using the Vectastatin Elite ABC Kit (Vector Laboratories Inc, Burlingame, CA, USA) according to the manufacturer's instructions and our previously published methods ${ }^{4,5}$. For epitope retrieval, deparaffinized and rehydrated slides were placed in a plastic jar with a boiling solution of $1 \mathrm{mM}$ ethylenediaminetetraacetic acid (EDTA) ( $\mathrm{pH}$ 8.0) for 20 minutes. The following primary antibodies were used: rabbit anti-ST2 polyclonal antibody (working dilution 1:100; Thermo Fisher Scientific, USA) and mouse anti-FoxP3 monoclonal antibody (working dilution 1:100, Abcam, UK). Tissue sections were incubated with the primary antibodies at $4{ }^{\circ} \mathrm{C}$ overnight. Then, the chromogen 3-amino-9-ethylcarbazole (AEC; Vector Laboratories, Burlingame, CA, USA) was used to detect the target antigens, and the tissues were counterstained with Mayer's hematoxylin. Previous known tumor sections positive for ST2 and FoxP3 were used as positive controls to confirm the immunoreactivity of ST2 and FoxP3 in each series of IHCs. To exclude background staining 


\begin{tabular}{|c|c|c|c|}
\hline Assay & & Primer & Sequence \\
\hline \multirow{3}{*}{$\beta$-actin } & \multirow{3}{*}{ TaqMan } & Forward & 5' TGCCGACAGGATGCAGAAG $3^{\prime}$ \\
\hline & & Reverse & 5' GCCGATCCACACGGAGTACT 3' \\
\hline & & Probe & $\begin{array}{l}\text { FAM 5' AGATCAAGATCATTGCTCCTCCTGAGCGC 3' } \\
\text { TAMRA }\end{array}$ \\
\hline \multirow{3}{*}{ FoxP3-977 } & \multirow{3}{*}{ TaqMan } & Forward & 5' GAGAAGCTGAGTGCCATGCA 3' \\
\hline & & Reverse & 5' GGAGCCCTTGTCGGATGAT 3' \\
\hline & & Probe & FAM 5'AATGGCACTGACCAAGGCTTCATCTGTG 3' BHQ \\
\hline \multirow{3}{*}{ ST2 } & \multirow{3}{*}{ TaqMan } & Forward & purchased from Life Technologies (Cat\# No. 4331182) \\
\hline & & Reverse & purchased from Life Technologies (Cat\# No. 4331182) \\
\hline & & Probe & purchased from Life Technologies (Cat\# No. 4331182) \\
\hline
\end{tabular}

Table 3. Primer/probe sequences of house-keeping gene, ST2 and FoxP3 for quantitative real-time PCR.

by nonspecific antibody binding, negative controls were included using isotype-matched antibodies in each IHC test.

Double immunohistochemistry. To check whether FoxP3-positive cells infiltrated into adenoma/CRC epithelium were Tregs instead of epithelial cells, double immunohistochemistry with FoxP3/CD3 (Rabbit polyclonal antibody, DAKO, Carpinteria, CA, USA) antibodies was performed with an EnVision G|2 doublestain dystem, rabbit/mouse kit (DAKO, Carpinteria, CA, USA) according to the protocol described in our previous publication $^{73}$. In addition, the expression of ST2 in the FoxP3 positive Tregs with ST2/FoxP3 antibodies was examined with the same method. FoxP3-IR was developed with DAB substrate (brown color), and CD3-IR and ST2-IR were with permanent red substrate (red color). Since FoxP3 is positive in cell nuclear, nuclear counterstain with hematoxylin was not applied.

Double immunofluorescence (DIF). To examine the expression of ST2 on Treg cells in the adenoma/CRC microenvironment, DIF was performed with antibodies against ST2/FoxP3 in the selected sections of 10 normal controls, 10 adenomas and 10 CRCs according to the protocol described in our previous publications ${ }^{1,5}$. The immunoreactivity (IR) of FoxP3 was developed with a Texas red-conjugated secondary antibody, and ST2-IR was developed with a fluorescein isothiocyanate (FITC)-conjugated secondary antibody (both antibodies obtained from Jackson ImmunoRearch Lab., West Grove, PA, USA). Nuclear counterstaining was not applied.

To define the phenotypes of ST2-positive cells in adenoma/CRC stroma, DIFs with ST2/CD3 (Mouse monoclonal antibody, DAKO, Carpinteria, CA, USA) antibodies were performed according to the protocol described in our previous publications ${ }^{1,5}$. CD3-IR were developed with a Cy3-conjugated, and ST2-IR was developed with a fluorescein isothiocyanate (FITC)-conjugated secondary antibodies.

Negative controls were routinely performed in each DIF: (1) sections with isotype-matched antibodies incubation were used; (2) secondary antibodies were substituted with phosphate buffered saline (PBS) in each double immunofluorescence test.

Morphometric analysis of IHC sections. Since we have observed that ST2-positive cells and FoxP3-positive Tregs were found in both the lamina propria and epithelium, we therefore evaluated their numbers in the lamina propria and epithelium according to the method described in our previous publications $s^{1,66}$. ST2-positive cells and FoxP3-positive Tregs in the adenoma/CRC stroma can be clearly viewed and counted, therefore, densities of ST2-positive cells or FoxP3-positive Tregs in the stroma, were semi-quantitatively scored in at least 3 high-power fields $(\mathrm{HPF}, \times 400)$ with abundant distribution from each slide as follows: nil (0), 1-19 cells/ field (1+), 20-49 cells/field (2+) and over 50 cells/field (3+). Whereas ST2-positive cells in normal/adenoma/ CRC epithelial cell are diffusely stained and difficultly counted, ST2-positive cells and FoxP3-positive Tregs in the epithelium were graded on a scale of $0-3$, with 0 representing no detectable staining and $3+$ representing the strongest staining. Densities of ST2-positive cells or FoxP3-positive Tregs were scored by a histological researcher and a pathologist in a blinded manner respectively, then the average data were used as statistical analysis.

Statistical analysis. The results were expressed as mean \pm SEM (standard error of the mean) unless otherwise stated. Statistical significance was evaluated by the Mann-Whitney test or the Kruskal-Wallis test where appropriate. The correlation between the density of ST2-positive cells and the density of FoxP3-positive Tregs within the CRC microenvironment was analyzed using the nonparametric correlation Spearman's R coefficient analysis. CRC patients with different densities of ST2- or FoxP3-positive cells were divided into "high or "low" groups according to the median value of positive cell densities, Kaplan-Meier analysis was used to calculate survival rates and differences in survival curves were determined by the log-rank test. Values of $P<0.05$ were considered significant.

Ethical approval and informed consent. 1. Approval: Ethical approval was obtained by the Ethics Committee of University Hospital of North Norway.

2. Accordance: All procedures in this study were conducted in accordance with the Ethics Committee of University Hospital of North Norway.

3. Informed consent: Written informed consent was obtained from the patients. 


\section{Data availability}

Data to support this study were based on analysis of immunohistochemistry and histological diagnosis from patients with adenoma and CRC admitted to our hospital.

Received: 14 August 2019; Accepted: 13 March 2020; Published online: 03 April 2020

\section{References}

1. Cui, G. et al. Dynamics of the IL-33/ST2 network in the progression of human colorectal adenoma to sporadic colorectal cancer. Cancer Immunol Immunother 64, 181-190, https://doi.org/10.1007/s00262-014-1624-x (2015).

2. Shi, Y. et al. Changes of immunocytic phenotypes and functions from human colorectal adenomatous stage to cancerous stage: Update. Immunobiology 220, 1186-1196, https://doi.org/10.1016/j.imbio.2015.06.003 (2015).

3. Cui, G., Shi, Y., Cui, J., Tang, F. \& Florholmen, J. Immune microenvironmental shift along human colorectal adenoma-carcinoma sequence: is it relevant to tumor development, biomarkers and biotherapeutic targets? Scand J Gastroenterol 47, 367-377, https://doi. org/10.3109/00365521.2011.648950 (2012).

4. Cui, G., Yuan, A., Sun, Z., Zheng, W. \& Pang, Z. IL-1beta/IL-6 network in the tumor microenvironment of human colorectal cancer. Pathol Res Pract 214, 986-992, https://doi.org/10.1016/j.prp.2018.05.011 (2018).

5. Cui, G., Yuan, A., Zhu, L., Florholmen, J. \& Goll, R. Increased expression of interleukin-21 along colorectal adenoma-carcinoma sequence and its predicating significance in patients with sporadic colorectal cancer. Clin Immunol 183, 266-272, https://doi. org/10.1016/j.clim.2017.09.003 (2017).

6. Mager, L. F., Wasmer, M. H., Rau, T. T. \& Krebs, P. Cytokine-Induced Modulation of Colorectal Cancer. Front Oncol 6, 96, https:// doi.org/10.3389/fonc.2016.00096 (2016).

7. Donadon, M. et al. The Shifting Paradigm of Prognostic Factors of Colorectal Liver Metastases: From Tumor-Centered to Host Immune-Centered Factors. Front Oncol 8, 181, https://doi.org/10.3389/fonc.2018.00181 (2018).

8. Schmitz, J. et al. IL-33, an interleukin-1-like cytokine that signals via the IL-1 receptor-related protein ST2 and induces Thelper type 2-associated cytokines. Immunity 23, 479-490, https://doi.org/10.1016/j.immuni.2005.09.015 (2005).

9. Seidelin, J. B., Rogler, G. \& Nielsen, O. H. A role for interleukin-33 in T(H)2-polarized intestinal inflammation? Mucosal immunology 4, 496-502, https://doi.org/10.1038/mi.2011.22 (2011).

10. Ramadan, A., Land, W. G. \& Paczesny, S. Editorial: Danger Signals Triggering Immune Response and Inflammation. Frontiers in immunology 8, 979, https://doi.org/10.3389/fimmu.2017.00979 (2017).

11. Ohayon, D. et al. Interleukin-33 modulates human natural killer cell responses. Journal of Immunology 200(164), 121 (2018).

12. Matta, B. M. \& Turnquist, H. R. Expansion of Regulatory T Cells In Vitro and In Vivo by IL-33. Methods Mol Biol 1371, 29-41, https://doi.org/10.1007/978-1-4939-3139-2_3 (2016).

13. Nascimento, D. C. et al. IL-33 contributes to sepsis-induced long-term immunosuppression by expanding the regulatory T cell population. Nat Commun 8, 14919, https://doi.org/10.1038/ncomms14919 (2017).

14. Peine, M., Marek, R. M. \& Lohning, M. IL-33 in T Cell Differentiation, Function, and Immune Homeostasis. Trends Immunol 37, 321-333, https://doi.org/10.1016/j.it.2016.03.007 (2016).

15. Schiering, C. et al. The alarmin IL-33 promotes regulatory T-cell function in the intestine. Nature 513, 564-568, https://doi. org/10.1038/nature13577 (2014).

16. Maywald, R. L. et al. IL-33 activates tumor stroma to promote intestinal polyposis. Proc Natl Acad Sci USA 112, E2487-2496, https:// doi.org/10.1073/pnas.1422445112 (2015).

17. Zhang, Y. et al. IL-33 promotes growth and liver metastasis of colorectal cancer in mice by remodeling the tumor microenvironment and inducing angiogenesis. Molecular carcinogenesis 56, 272-287, https://doi.org/10.1002/mc.22491 (2017).

18. Cui, G. et al. Contribution of IL-33 to the Pathogenesis of Colorectal Cancer. Front. Oncol 8, https://doi.org/10.3389/fonc.2018.00561 (2018).

19. Liu, X. et al. IL-33/ST2 pathway contributes to metastasis of human colorectal cancer. Biochemical and biophysical research communications 453, 486-492, https://doi.org/10.1016/j.bbrc.2014.09.106 (2014).

20. Mertz, K. D. et al. The IL-33/ST2 pathway contributes to intestinal tumorigenesis in humans and mice. Oncoimmunology 5 , e1062966, https://doi.org/10.1080/2162402X.2015.1062966 (2016).

21. He, Z., Chen, L., Furtado, G. C. \& Lira, S. A. Interleukin 33 regulates gene expression in intestinal epithelial cells independently of its nuclear localization. Cytokine 111, 146-153, https://doi.org/10.1016/j.cyto.2018.08.009 (2018).

22. He, Z. et al. Epithelial-derived IL-33 promotes intestinal tumorigenesis in Apc (Min/+) mice. Sci Rep 7, 5520, https://doi. org/10.1038/s41598-017-05716-Z (2017).

23. Mazewski, C., Kim, M. S. \& Gonzalez de Mejia, E. Anthocyanins, delphinidin-3-O-glucoside and cyanidin-3-O-glucoside, inhibit immune checkpoints in human colorectal cancer cells in vitro and in silico. Sci Rep 9, 11560, https://doi.org/10.1038/s41598-01947903-0 (2019).

24. Jia, S., Li, W., Liu, P. \& Xu, L. X. A role of eosinophils in mediating the anti-tumour effect of cryo-thermal treatment. Sci Rep 9, 13214, https://doi.org/10.1038/s41598-019-49734-5 (2019).

25. Tubita, V. et al. Effect of immunosuppression in miRNAs from extracellular vesicles of colorectal cancer and their influence on the pre-metastatic niche. Sci Rep 9, 11177, https://doi.org/10.1038/s41598-019-47581-y (2019).

26. Lu, J., Kang, J., Zhang, C. \& Zhang, X. The role of IL-33/ST2L signals in the immune cells. Immunol Lett 164, 11-17, https://doi. org/10.1016/j.imlet.2015.01.008 (2015).

27. Wen, Y. H. et al. Stromal interleukin-33 promotes regulatory T cell-mediated immunosuppression in head and neck squamous cell carcinoma and correlates with poor prognosis. Cancer Immunol Immunother 68, 221-232, https://doi.org/10.1007/s00262-0182265-2 (2019).

28. Halvorsen, E. C. et al. IL-33 increases ST2(+) Tregs and promotes metastatic tumour growth in the lungs in an amphiregulindependent manner. Oncoimmunology 8, e1527497, https://doi.org/10.1080/2162402X.2018.1527497 (2019).

29. Ameri, A. H. et al. IL-33/regulatory T cell axis triggers the development of a tumor-promoting immune environment in chronic inflammation. Proc Natl Acad Sci USA 116, 2646-2651, https://doi.org/10.1073/pnas.1815016116 (2019).

30. Chaput, N. et al. Identification of CD8+CD25+Foxp3 + suppressive T cells in colorectal cancer tissue. Gut 58, 520-529, https://doi. org/10.1136/gut.2008.158824 (2009).

31. Clarke, S. L. et al. CD4+CD25+FOXP3+ regulatory T cells suppress anti-tumor immune responses in patients with colorectal cancer. PloS one 1, e129, https://doi.org/10.1371/journal.pone.0000129 (2006).

32. Katz, S. C. et al. Regulatory T cell infiltration predicts outcome following resection of colorectal cancer liver metastases. Annals of surgical oncology 20, 946-955, https://doi.org/10.1245/s10434-012-2668-9 (2013).

33. Ladoire, S., Martin, F. \& Ghiringhelli, F. Prognostic role of FOXP3 + regulatory T cells infiltrating human carcinomas: the paradox of colorectal cancer. Cancer Immunol Immunother 60, 909-918, https://doi.org/10.1007/s00262-011-1046-y (2011).

34. Le Gouvello, S. et al. High prevalence of Foxp3 and IL17 in MMR-proficient colorectal carcinomas. Gut 57, 772-779, https://doi. org/10.1136/gut.2007.123794 (2008). 
35. Loddenkemper, C. et al. In situ analysis of FOXP3+ regulatory T cells in human colorectal cancer. J Transl Med 4, 52, https://doi. org/10.1186/1479-5876-4-52 (2006).

36. Nagorsen, D. et al. Tumor-infiltrating macrophages and dendritic cells in human colorectal cancer: relation to local regulatory $\mathrm{T}$ cells, systemic T-cell response against tumor-associated antigens and survival. J Transl Med 5, 62, https://doi.org/10.1186/14795876-5-62 (2007).

37. Bacic, D., Uravic, M., Bacic, R., Sutic, I. \& Petrosic, N. Augmentation of regulatory T cells (CD4+CD25+Foxp3+) correlates with tumor stage in patients with colorectal cancer. Coll Antropol 35(Suppl 2), 65-68 (2011).

38. Ling, K. L. et al. Increased frequency of regulatory T cells in peripheral blood and tumour infiltrating lymphocytes in colorectal cancer patients. Cancer Immun 7, 7 (2007).

39. Michel, S. et al. High density of FOXP3-positive T cells infiltrating colorectal cancers with microsatellite instability. Br J Cancer $\mathbf{9 9}$, 1867-1873, https://doi.org/10.1038/sj.bjc.6604756 (2008).

40. Deng, L. et al. Accumulation of foxp3+ T regulatory cells in draining lymph nodes correlates with disease progression and immune suppression in colorectal cancer patients. Clin Cancer Res 16, 4105-4112, https://doi.org/10.1158/1078-0432.CCR-10-1073 (2010).

41. Frey, D. M. et al. High frequency of tumor-infiltrating FOXP3(+) regulatory T cells predicts improved survival in mismatch repairproficient colorectal cancer patients. Int J Cancer 126, 2635-2643, https://doi.org/10.1002/ijc.24989 (2010).

42. Salama, P. et al. Tumor-infiltrating FOXP3+ T regulatory cells show strong prognostic significance in colorectal cancer. J Clin Oncol 27, 186-192, https://doi.org/10.1200/JCO.2008.18.7229 (2009).

43. Suzuki, H. et al. Intratumoral CD8 $(+)$ T/FOXP3 $(+)$ cell ratio is a predictive marker for survival in patients with colorectal cancer. Cancer Immunol Immunother 59, 653-661, https://doi.org/10.1007/s00262-009-0781-9 (2010).

44. Akeus, P. et al. Altered chemokine production and accumulation of regulatory T cells in intestinal adenomas of APC mice. Cancer Immunol Immunother, https://doi.org/10.1007/s00262-014-1555-6 (2014).

45. Noel, G. et al. Ablation of interaction between IL-33 and ST2+ regulatory T cells increases immune cell-mediated hepatitis and activated NK cell liver infiltration. Am J Physiol Gastrointest Liver Physiol 311, G313-323, https://doi.org/10.1152/ajpgi.00097.2016 (2016).

46. Popovic, B. et al. IL-33/ST2 pathway drives regulatory T cell dependent suppression of liver damage upon cytomegalovirus infection. PLoS Pathog 13, e1006345, https://doi.org/10.1371/journal.ppat.1006345 (2017).

47. Zhu, J. et al. IL-33 induces both regulatory B cells and regulatory T cells in dextran sulfate sodium-induced colitis. Int Immunopharmacol 46, 38-47, https://doi.org/10.1016/j.intimp.2017.02.006 (2017).

48. Fournie, J. J. \& Poupot, M. The Pro-tumorigenic IL-33 Involved in Antitumor Immunity: A Yin and Yang. Cytokine. Frontiers in immunology 9, 2506, https://doi.org/10.3389/fimmu.2018.02506 (2018).

49. Hong, J., Kim, S. \& Lin, P. C. Interleukin-33 and ST2 Signaling in Tumor Microenvironment. J Interferon Cytokine Res 39, 61-71, https://doi.org/10.1089/jir.2018.0044 (2019).

50. Xiao, P. et al. Interleukin 33 in tumor microenvironment is crucial for the accumulation and function of myeloid-derived suppressor cells. Oncoimmunology 5, e1063772, https://doi.org/10.1080/2162402X.2015.1063772 (2016).

51. Pastille, E. et al. The IL-33/ST2 pathway shapes the regulatory T cell phenotype to promote intestinal cancer. Mucosal Immunol 12, 990-1003, https://doi.org/10.1038/s41385-019-0176-y (2019).

52. Landskron, G. et al. Interleukin 33/ST2 Axis Components Are Associated to Desmoplasia, a Metastasis-Related Factor in Colorectal Cancer. Frontiers in immunology 10, 1394, https://doi.org/10.3389/fimmu.2019.01394 (2019).

53. Li, Y. et al. IL-33 facilitates proliferation of colorectal cancer dependent on COX2/PGE2. J Exp Clin Cancer Res 37, 196, https://doi. org/10.1186/s13046-018-0839-7 (2018).

54. Brudvik, K. W., Henjum, K., Aandahl, E. M., Bjornbeth, B. A. \& Tasken, K. Regulatory T-cell-mediated inhibition of antitumor immune responses is associated with clinical outcome in patients with liver metastasis from colorectal cancer. Cancer Immunol Immunother 61, 1045-1053, https://doi.org/10.1007/s00262-011-1174-4 (2012).

55. Mahic, M., Yaqub, S., Johansson, C. C., Tasken, K. \& Aandahl, E. M. FOXP3+CD4+CD25+ adaptive regulatory T cells express cyclooxygenase-2 and suppress effector T cells by a prostaglandin E2-dependent mechanism. J Immunol 177, 246-254, https://doi. org/10.4049/jimmunol.177.1.246 (2006).

56. Siede, J. et al. IL-33 Receptor-Expressing Regulatory T Cells Are Highly Activated, Th2 Biased and Suppress CD4 T Cell Proliferation through IL-10 and TGFbeta Release. PloS one 11, e0161507, https://doi.org/10.1371/journal.pone.0161507 (2016).

57. Cui, G., Yuan, A., Goll, R. \& Florholmen, J. IL-17A in the tumor microenvironment of the human colorectal adenoma-carcinoma sequence. Scand J Gastroenterol 47, 1304-1312, https://doi.org/10.3109/00365521.2012.725089 (2012).

58. Cui, J. et al. The expression of non-mast histamine in tumor associated microvessels in human colorectal cancers. Pathology oncology research: POR 19, 311-316, https://doi.org/10.1007/s12253-012-9584-y (2013).

59. Sievers, C. K., Leystra, A. A., Clipson, L., Dove, W. F. \& Halberg, R. B. Understanding Intratumoral Heterogeneity: Lessons from the Analysis of At-Risk Tissue and Premalignant Lesions in the Colon. Cancer prevention research 9, 638-641, https://doi. org/10.1158/1940-6207.CAPR-16-0096 (2016).

60. Cui, G. et al. Cellular and clinicopathological features of the IL-33/ST2 axis in human esophageal squamous cell carcinomas. Cancer Cell Int 18, 203, https://doi.org/10.1186/s12935-018-0700-2 (2018).

61. Hu, L. A., Fu, Y., Zhang, D. N. \& Zhang, J. Serum IL-33 as a diagnostic and prognostic marker in non- small cell lung cancer. Asian Pacific journal of cancer prevention: APJCP 14, 2563-2566, https://doi.org/10.7314/apjcp.2013.14.4.2563 (2013).

62. Jovanovic, I. P. et al. Interleukin-33/ST2 axis promotes breast cancer growth and metastases by facilitating intratumoral accumulation of immunosuppressive and innate lymphoid cells. Int J Cancer 134, 1669-1682, https://doi.org/10.1002/ijc.28481 (2014).

63. Zhou, Y., Ji, Y., Wang, H., Zhang, H. \& Zhou, H. IL-33 Promotes the Development of Colorectal Cancer Through Inducing TumorInfiltrating ST2L $(+)$ Regulatory T Cells in Mice. Technol Cancer Res Treat 17, 1533033818780091, https://doi. org/10.1177/1533033818780091 (2018).

64. Kmieciak, M. et al. Human T cells express CD25 and Foxp3 upon activation and exhibit effector/memory phenotypes without any regulatory/suppressor function. J Transl Med 7, 89, https://doi.org/10.1186/1479-5876-7-89 (2009).

65. Cui, G., Li, Z., Ren, J. \& Yuan, A. IL-33 in the tumor microenvironment is associated with the accumulation of FoxP3-positive regulatory T cells in human esophageal carcinomas. Virchows Arch https://doi.org/10.1007/s00428-019-02579-9 (2019).

66. Hua, W. et al. Accumulation of FoxP3 + T regulatory cells in the tumor microenvironment of human colorectal adenomas. Pathol Res Pract 212, 106-112, https://doi.org/10.1016/j.prp.2015.12.002 (2016).

67. Bustin, S. A. \& Nolan, T. Pitfalls of quantitative real-time reverse-transcription polymerase chain reaction. J Biomol Tech 15, 155-166 (2004).

68. Chaillou, T. et al. Pitfalls in target mRNA quantification for real-time quantitative RT-PCR in overload-induced skeletal muscle hypertrophy. Physiol Genomics 43, 228-235, https://doi.org/10.1152/physiolgenomics.00109.2010 (2011).

69. Phillips, S. M. et al. Tumour-infiltrating lymphocytes in colorectal cancer with microsatellite instability are activated and cytotoxic. Br J Surg 91, 469-475, https://doi.org/10.1002/bjs.4472 (2004).

70. Chen, S. F. et al. The paracrine effect of cancer-associated fibroblast-induced interleukin-33 regulates the invasiveness of head and neck squamous cell carcinoma. The Journal of pathology 231, 180-189, https://doi.org/10.1002/path.4226 (2013).

71. Sun, P. et al. Serum interleukin-33 levels in patients with gastric cancer. Dig Dis Sci 56, 3596-3601, https://doi.org/10.1007/s10620011-1760-5 (2011). 
72. Cui, G. et al. Improvement of real-time polymerase chain reaction for quantifying TNF-alpha mRNA expression in inflamed colorectal mucosa: an approach to optimize procedures for clinical use. Scand J Clin Lab Invest 66, 249-259, https://doi. org/10.1080/00365510600590472 (2006).

73. Cui, G., Yuan, A., Vonen, B. \& Florholmen, J. Progressive cellular response in the lamina propria of the colorectal adenomacarcinoma sequence. Histopathology 54, 550-560 (2009).

\section{Acknowledgements}

This project was supported by the Medical Research Program, Northern Norway Regional Health Authority (Program No. SFP-44-04), the Innovation Scientists and Technicians Troop Construction Projects of Henan Province (CXTD20150009), and the Nature and Science Foundation of Henan Province (Program No. 182300410326), China. We would like to thank the patients for their collaboration and their participation in the present study. Finally, we would like to thank Ingrid Christiansen for her great technique help.

\section{Author contributions}

G.C., R.G. and F.J. were involved in designing experiment and analyzing results, Y.A. and L.Z. were involved in conducting experiments, G.C. and R.G. were involved in drafting the article or revising it critically for important intellectual content. All authors have read and approved the final version of the manuscript.

\section{Competing interests}

The authors declare no competing interests.

\section{Additional information}

Supplementary information is available for this paper at https://doi.org/10.1038/s41598-020-62502-0.

Correspondence and requests for materials should be addressed to G.C.

Reprints and permissions information is available at www.nature.com/reprints.

Publisher's note Springer Nature remains neutral with regard to jurisdictional claims in published maps and institutional affiliations.

Open Access This article is licensed under a Creative Commons Attribution 4.0 International License, which permits use, sharing, adaptation, distribution and reproduction in any medium or format, as long as you give appropriate credit to the original author(s) and the source, provide a link to the Creative Commons license, and indicate if changes were made. The images or other third party material in this article are included in the article's Creative Commons license, unless indicated otherwise in a credit line to the material. If material is not included in the article's Creative Commons license and your intended use is not permitted by statutory regulation or exceeds the permitted use, you will need to obtain permission directly from the copyright holder. To view a copy of this license, visit http://creativecommons.org/licenses/by/4.0/.

(c) The Author(s) 2020 